\title{
Comportamento ingestivo de novilhas Nelore em pastejo recebendo suplemento a base de própolis ou monensina sódica
}

\section{Ingestive behavior of Nellore heifers grazing receiving the supplement based on propolis or monensin}

\author{
Luiz Juliano Valério Geron ${ }^{1 *}$; Lúcia Maria Zeoula ${ }^{2}$; Emerson Henri Yoshimura ${ }^{3}$; \\ Selma Lucy Franco ${ }^{2}$; Marcos Chiquitelli Neto ${ }^{4}$; Eduardo Marostegan Paula ${ }^{5}$; \\ Rafael Barreiros Samensari ${ }^{5}$; Lucimar Pontara Peres ${ }^{2}$
}

\begin{abstract}
Resumo
Avaliou-se o efeito dos aditivos a base de própolis e monensina sódica sobre o comportamento ingestivo (pastejo - PAS, ruminação deitado - RDE, ruminação em pé - RPE, ruminação - RU, ócio deitado ODE, ócio em pé - OPE, ócio - OC, andando - AND, postura em pé - PE, postura deitado - DE e consumo de suplemento e água - CSA) de novilhas em pastejo de capim Tifton 85. Os tratamentos avaliados foram: ausência de aditivo (AAD); própolis - PRO (33,24 mg animal ${ }^{-1}$ de flavonóides totais em apigenina); e monensina sódica - MON (100 $\left.\mathrm{mg}^{\text {animal }}{ }^{-1}\right)$. Foram utilizadas cinco novilhas tratamento $\mathrm{o}^{-1}$ para o ensaio do comportamento ingestivo durante 12 horas de avaliação total por dia, o qual foi dividido em três períodos de avaliação. Foi utilizado um delineamento em fatorial $3 \times 3$ para avaliação do comportamento ingestivo em função dos períodos de avaliação. Foram utilizados três piquetes de 2,9 hectares de capim Tifton 85. Os aditivos e o suplemento mineral (50 $\left.\mathrm{g} \mathrm{animal}^{-1}\right)$ foram veiculados juntamente com $200 \mathrm{~g}$ de grão de milho moído fornecido às 17 horas. Para todas as atividades dos comportamentos ingestivo foram observados o efeito de período sobre os tempos despendidos nas diferentes atividades. As atividades de PAS e CSA foram maiores no terceiro período avaliado (15horas às 19 horas) em relação ao primeiro período (7horas às 11 horas). Para a atividade $\mathrm{OC}$ e DE, foi observado maior tempo expresso em minutos para as novilhas do tratamento com PRO no período das 7 horas às 11 horas, em relação aos demais tratamentos (AAD e MON). Desta maneira, conclui-se que a utilização de aditivo a base de própolis possibilita a substituição a monensina sódica para novilhas mantidas a pasto sem alterar o comportamento ingestivo além de propiciar maior período ócio durante o dia sem alterar o desempenho animal.
\end{abstract}

Palavras-chave: Ócio, pastejo, ruminação, suplementação

\begin{abstract}
We evaluated the effect of additives the basis of propolis and monensin on ingestive behavior (grazing - GRA, rumination lying - RLY, rumination in foot - RFO, rumination - RUM; idleness lying - ILY, idleness in standing - IDS, idleness - IDL, walking - WAL, posture standing - POS, posture lying - PLY, intake of supplement and water - ISW) of heifers in Tifton 85 grazing. The treatments were: no additive (NAD); propolis - PRO (33.24 mg animal ${ }^{-1}$ of total flavonoid in apigenin), and monensin - MON (100

\footnotetext{
${ }^{1}$ Prof. Dr., Universidade do Estado de Mato Grosso, UNEMAT, Pontes e Lacerda, MT. E-mail: ljgeron@yahoo.com.br

${ }^{2}$ Profs. Drs., Universidade Estadual de Maringá, UEM, Maringá, PR. E-mail:1mzeoula@uem.br; slfrano@uem.br; lucimarbee1@ yahoo.com.br

3 Discente de Doutorado, UEM, Maringá, PR. E-mail: ehy@veterinario.med.br

${ }^{4}$ Prof. Dr., Universidade Estadual Paulista Júlio de Mesquita Filho, UNESP, Ilha Solteira, SP. E-mail: machine@bio.feis.unesp.br

${ }^{5}$ Discentes de Mestrado, UEM, Maringá, PR. E-mail: eduardo_zoouem@yahoo.com.br; raphael@hotmail.com

* Autor para correspondência
} 
mg animal ${ }^{-1}$ ). Were used five heifers treatment ${ }^{-1}$ for evaluation of ingestive behavior during 12 hours of total valuation, which was divided into three periods. Used a factorial design into $3 \times 3$ for evaluation of ingestive behavior as a function of the evaluation periods. Were utilized three paddocks of 2.9 acres of grass Tifton 85. The additives and mineral supplement $\left(50 \mathrm{~g} \mathrm{animal}^{-1}\right)$ were provided with $200 \mathrm{~g}$ of corn meal to 17 hours. For all activities of the ingestive behaviors observed the effect of period on the time spent on of different activities. The activities of GRA and ISW were higher in the third period (15hours to 19hours) compared to the first period (7hours at 11hours). For IDL and PLY, there was a higher time in minutes for heifers treatment with PRO in the period of 7 hours at 11 hours, compared to other treatments (NAD and MON). Thus, it is concluded that the use of the additive based on propolis enables sodium monensin replacement, to heifers maintained on pasture without changing eating behavior as well as providing greater idleness during the day the without affecting animal performance.

Key words: Idleness, grazing, ruminating, supplementation

\section{Introdução}

Com o crescimento da produção de carne no Brasil os setores responsáveis por otimizar a cadeia produtiva têm criado meios de chegar a uma maior produção deste alimento em menor espaço de tempo, por meio da utilização de aditivos alimentares que modificam a fermentação ruminal a fim de melhorar a conversão alimentar com melhorias na eficiência produtiva (OTERO, 2008).

A utilização de aditivos na nutrição animal tem sido preconizada em situações nas quais objetivase a maximização do valor nutritivo da dieta e conseqüentemente alcançar maior eficiência produtiva a baixo custo de produção.

Estudos estão sendo realizado em busca de produtos alternativos e naturais que possam agir da mesma maneira ou de forma semelhante aos dos ionóforos, porém, não sejam sintéticos e não causem problemas para os animais e para as pessoas que vão consumir seus produtos. Diante deste fato a própolis tem mostrado essas características, sendo necessários estudos mais aprofundados sobre a sua utilização na alimentação de animais ruminantes e seu efeito sobre a microflora ruminal (PRADO, 2005).

Várias pesquisas foram realizadas para identificar a composição química da própolis, estes estudos identificaram mais de 300 compostos químicos na própolis, entre eles flavonóides, ácidos graxos, ácidos aromáticos, terpenóides, aldeídos, álcoois, ácidos alifáticos, ésteres, aminoácidos, esteróides e açúcares (GREENWAY; SCAYSBROOK; WHATLEY, 1990; BANKOVA; DYULGEROV; POPOV, 1992; PEREIRA; SEIXAS; AQUINO NETO, 2002). O maior grupo é dos flavonóides (flavonas, flavonóis, flavononas, dihidroflavonóis), assim como minerais e vitaminas, os quais são descritos como principais responsáveis pela atividade antimicrobiana.

Estudos realizados por Freitas et al. (2009), para avaliar o extrato etanoico de própolis na alimentação de vacas leiteiras demonstraram que este aditivo não alterou o consumo de matéria seca (MS) das vacas em lactação porém aumentou significativamente a produção de leite. Os autores concluíram que o extrato de própolis é um aditivo importante a ser utilizado na nutrição animal uma vez que auxilia a manutenção da condição ruminal em vacas leiteiras.

A avaliação do extrato etanólico de própolis sobre a ingestão de MS de cabras leiteiras foi conduzido por Lana et al. (2007) que não observaram efeito deste aditivo sobre o consumo de MS de cabras alimentadas com $67 \%$ de silagem de milho e $33 \%$ de concentrado, porém os pesquisadores relataram que novos estudos deveriam ser realizados com a adição de própolis na alimentação de ruminantes, uma vez que existem efeitos antimicrobianos comprovados in vitro (OLIVEIRA et al., 2006; PRADO et al., 2010) e estes devem ser testados in vivo.

Como o Brasil é um grande produtor de bovinos o estudo sobre a etologia, ou seja, o estudo do comportamento e das manifestações vitais dos 
animais em seu ambiente de criação ou em ambiente modificado pelo homem (SOUZA, 2007) vem sendo cada vez mais utilizada para animais ruminantes produzidos a pasto.

Estudo realizado por Faria et al. (2011), para avaliar o comportamento ingestivo de bovinos inteiros confinados alimentados com produtos a base de própolis (LLOS) demonstrou que as diferentes doses do LLOS não alterou as atividades do comportamento ingestivo (consumo de MS, ingestão de água e as atividade de andar, ruminar em pé, ruminar deitado, em pé e deitado).

O conhecimento do comportamento dos animais é essencial para a obtenção de condições ótimas de criação e alimentação, podendo, desta forma alcançar o máximo de eficiência produtiva (SWENSON; DUKES, 1988).

Pesquisas realizadas por Gary, Sherritt e Hale (1970) e Salla et al. (1999) demonstraram que o tipo de estudo para avaliar o tempo médio diário de ingestão, ruminação e descanso pode ser realizado com a escala de 5 a 15 minutos entre as observações, e que estes resultados não diferiram estatisticamente dos encontrados pelo processo contínuo de observação.

O desempenho animal relaciona-se diretamente com o consumo diário de forragem e indiretamente com os efeitos que o processo de pastejo tem sobre a composição da forragem, a estrutura do relvado (dossel) e a produtividade do pasto (COSGROVE, 1997). Os fatores que influenciam o consumo e os mecanismos que o regulam são vários e não são completamente conhecidos (WALDO, 1986; MERTENS, 1994; ZANINE, et al., 2006). O ambiente e o clima são fatores que podem alterar o consumo alimentar de animais mantidos a pasto.

Os ruminantes ao ingerirem, mastigam o alimento superficialmente, sendo este transportado até o rúmen e retículo e após algum tempo, esse alimento retorna a boca para a ruminação que é uma atividade que permite a redução do tamanho da partícula dos alimentos, favorecendo, a degradação e digestão destes, melhorando a absorção dos nutrientes (COSGROVE, 1997).

O tempo total de ruminação pode variar de quatro até nove horas, sendo dividido em períodos de poucos minutos a mais de uma hora. A atividade de ruminação pode ocorrer com o animal em pé ou deitado, sendo que esta última posição demonstra uma condição de conforto e bem estar animal. O tempo em que o animal não está ingerindo alimento, água e ruminando é considerado de ócio. Esse tempo pode variar com as estações do ano, sendo maior durante os meses mais quentes (MARQUES, 2000).

A atividade de ruminação em animais adultos ocupa em torno de 8 horas por dia com variações entre 4 e 9 horas, divididas em 15 a 20 períodos (FRASER, 1980; VAN SOEST, 1994).

Esse comportamento é influenciado pela natureza da dieta e parece ser proporcional ao teor de parede celular dos alimentos volumosos (VAN SOEST, 1994). Entretanto, Welch e Hooper (1982) afirmaram que o aumento de fibra indigestível não incrementa a ruminação por mais de 9 horas dia $^{-1}$.

$\mathrm{O}$ ócio e as atividades que não incluem a alimentação e ruminação perfazem cerca de 10 horas (ALBRIGHT, 1993), com variações entre 9 e 12 horas por dia (FRASER, 1980; ORR; RUTTER; PENNING, 2001; PHILLIPS; RIND, 2001). Alimentos concentrados e fenos finamente triturados ou peletizados reduzem o tempo de ruminação, enquanto volumosos com alto teor de parede celular tendem a aumentar. $\mathrm{O}$ aumento do consumo tende a reduzir o tempo de ruminação por grama de alimento, fator provavelmente responsável pelo aumento de tamanho das partículas fecais, quando o consumo é elevado.

Damasceno, Bacarri Junior e Targa (1999) verificaram que há uma preferência dos animais em ruminar deitados, sendo que as maiores freqüências de ruminação ocorrem entre às 22 e às 5 horas e as maiores freqüências de ócio ocorrem normalmente, entre 11 e 14 horas, estabilizando- se das 22 às 7 horas. Enquanto que Farinatti et al. (2004), avaliaram 
o hábito de pastejo de bovinos em pastagem natural, observaram que a taxa de ruminação variou entre 5,23 e 9,88 horas e de ócio variou entre 3,7 e 6,8 horas.

Os bovinos produzidos a pasto procuram escolher seu alimento (através do comportamento ingestivo), o qual apresenta sob diferentes tipos de estrutura e qualidade e com abundancia variável no tempo e espaço (O'REAGAIN; METINS, 1989). Esses mecanismos desenvolvidos ao longo dos anos permitem aos herbívoros colherem uma dieta de qualidade superior aquela presente na média do ambiente (pasto).

Segundo Farinatti et al. (2004), o conhecimento dos horários de concentração do pastejo dos animais é de suma importância para o melhor aproveitamento das pastagens, bem como para o estabelecimento de estratégias adequadas de manejo.

As variáveis de comportamento não são de simples quantificação, pois englobam a questão de como o animal percebe e se movimenta no ambiente de pastejo (SARMENTO, 2003). No uso do tempo em pastejo, os animais procuram ser eficientes uma vez que buscam bocados potenciais enquanto mastigam a forragem apreendida em bocados anteriores (PRACHE, 1997).

Estudo conduzido por Prache (1997) demonstrou que as plantas podem apresentar algumas características correlacionadas com a facilidade de colheita da forragem pelo animal, entre elas destacam-se a altura do dossel forrageiro, a massa de forragem presente por unidade de volume, a baixa fibrosidade das laminas foliares, a disposição espacial dos tecidos vegetais preferidos, a presença de barreiras a desfolhação tais como bainhas e colmos e seu teor de matéria seca.

Estudo realizado por Carvalho et al. (2006), para avaliar o comportamento ingestivo de cabras Alpinas em lactação alimentadas com dietas contendo diferentes níveis de fibra em detergente neutro provenientes de forragem (Cynodon, sp) demonstrou que a quantidade de fibra na dieta de cabras em lactação propiciou incremento no tempo utilizado na alimentação (consumo de MS) e ruminação, portando promoveu aumento no tempo diário despendido na mastigação total e como consequência houve diminuição do tempo de ócio.

Portanto, existem poucas informações sobre a utilização de aditivos à base de própolis fornecidos a novilhas a pasto, desta forma o objetivo do presente estudo foi avaliar a adição de aditivo a base de própolis ou monensina sódica no suplemento de novilhas Nelores mantidas em pastejo de capim Tifton 85 sobre o comportamento ingestivo.

\section{Material e Métodos}

O experimento foi conduzido na Fazenda do Centro de Ensino Superior de Maringá (CESUMAR) localizada no município de Maringá - PR, em conjunto com o Departamento de Zootecnia da Universidade Estadual de Maringá - UEM.

Para o ensaio de desempenho animal foram utilizadas 54 novilhas da raça Nelore, com 24 meses de idade, com peso corporal médio inicial de 305,6 $\pm 11,7 \mathrm{~kg}$. Todos os animais foram everminados no início do experimento com medicamento a base de doramectina (Dectomax ${ }^{\circledR}$, Pfizer), identificadas por meio de ferro candente e também por brincos com cores diferentes por tratamento. Para formação dos lotes as novilhas foram distribuídas de acordo com o peso e alocadas ao acaso nos diferentes tratamentos.

Estabeleceu-se para a avaliação do desempenho animal, caracterização da forragem e produção de massa forrageira três períodos experimentais, os quais foram designados de meses, com duração média de 28 dias. Foram considerados os meses de janeiro, fevereiro e março.

A área experimental foi dividida em três piquetes por meio de cerca elétrica com três fios. A forrageira utilizada foi o capim Tifton 85 Cynodon dactylon (L.) Pers, estabelecida há dois anos e com área total de 8,7 hectares $\left(2,9\right.$ ha piquete $\left.^{-1}\right)$. Cada piquete possuía um bebedouro, um cocho de sal mineral, e 
cocho de polietileno com área individual de $0,50 \mathrm{~m}$ animal $^{-1}$ piquete $^{-1}$ para receber a suplementação energético-mineral.

Previamente ao início do experimento, os animais foram alocados por 28 dias nos piquetes (mês de dezembro) para adaptação à pastagem e aos tratamentos, que consistiram em suplementos sem adição de aditivos (AAD); e com os aditivos própolis (PRO) ou monensina sódica (MON).

$\mathrm{O}$ produto à base de própolis fornecido juntamente com o suplemento energético-mineral (veículo) apresentou concentração de própolis entre 5 a 30 g e diluição alcoólica entre 60,0 a 93,8\% ( $\left.\mathrm{v} \mathrm{v}^{-1}\right)$ e foi preparado de acordo com a metodologia desenvolvida por Franco e Bueno (1999) e constituído em um extrato seco de própolis, registrado no Instituto Nacional de Propriedade Industrial sob $\mathrm{n}^{\circ} 0605768-3$.
A preparação do extrato seco de própolis consistiu na extração hidroalcoólica da própolis bruta, a fim de liberar suas substâncias ativas (flavonoides e ácidos fenólicos). Subsequentemente, o conteúdo alcoólico foi evaporado com o auxílio de um rotaevaporador e o extrato foi seco em um spray dryer. A quantificação de flavonoides obtida por cromatografia líquida de alta eficiência (CLAE) foi de 33,24 mg animal-1 dia $^{-1}$ de flavonóides totais em apigenina.

A quantidade de monensina sódica fornecida foi de $100 \mathrm{mg}_{\text {animal }}{ }^{-1} \mathrm{dia}^{-1}$ (Rumensin ${ }^{\circledR}$ 200, Elanco) adicionada ao suplemento energético-mineral (veículo). Os aditivos e o suplemento mineral foram veiculados juntamente com o grão de milho moído, sendo esta mistura (250 $\mathrm{g}$ animal $\left.^{-1}\right)$ fornecida diariamente às 17 horas. A composição percentual do suplemento energético-mineral está apresentada na Tabela 1.

Tabela 1. Composição percentual dos suplementos energético-mineral $\left(\mathrm{g} \mathrm{kg}^{-1}\right)$.

\begin{tabular}{lccc}
\hline Ingredientes $\left(\mathrm{g} \mathrm{kg}^{-1}\right)$ & \multicolumn{3}{c}{ Tratamentos } \\
\cline { 2 - 4 } & $\mathrm{AAD}$ & PRO & MON \\
\hline Grão de milho moído & 800,0 & 780,0 & 780,0 \\
Minerais $^{1}$ & 200,0 & 200,0 & 200,0 \\
Própolis & - & 20,0 & - \\
Monensina sódica $^{2}$ & - & - & 20,0 \\
\hline
\end{tabular}

${ }^{1}$ Suplemento mineral (P40, Fortmix): Ca: $110 \mathrm{~g} \mathrm{~kg}^{-1}, \mathrm{P}: 40 \mathrm{~g} \mathrm{~kg}^{-1}$, Na: $140 \mathrm{~g} \mathrm{~kg}^{-1}, \mathrm{~S}: 8 \mathrm{~g} \mathrm{~kg}^{-1}, \mathrm{Mg}: 750$ mg kg-1, $\mathrm{Co}^{2} 45$ mg kg-1 I: 45 $\mathrm{mg} \mathrm{kg}{ }^{-1}$, Co: $825 \mathrm{mg} \mathrm{kg}^{-1}$, Se: $13 \mathrm{mg} \mathrm{kg}^{-1}$, Zn: $2200 \mathrm{mg} \mathrm{kg}^{-1}$, Fe: $400 \mathrm{mg} \mathrm{kg}^{-1}$; ${ }^{2}$ Rumensin ${ }^{\circledR} 200$ (Elanco); AAD: ausência de aditivo; PRO: própolis; MON: monensina sódica.

Fonte: Elaboração dos autores.

Para o ensaio de desempenho animal a pesagem dos animais foi realizada, sempre em jejum prévio de 9 horas, no início do experimento em janeiro e ao final de cada período experimental (mês), correspondente a 28 dias até completar 85 dias no final do mês de março. O ganho de peso corporal (GPC) foi obtido pela diferença entre o peso corporal (PC) final de cada mês e o PC inicial das novilhas.
O ganho médio diário (GMD) foi calculado pela divisão do GPC pelo número de dias de cada mês (28; 56 e 85 dias) como demonstrado na Tabela 2. $\mathrm{O}$ ganho de peso corporal vivo por hectare (GPV $\mathrm{ha}^{-1}$ ) foi obtido multiplicando o número de animais dia $^{-1}$ ha $^{-1}$ pelo GMD dos animais, multiplicado pelo número de dias de cada mês. 
Tabela 2. Desempenho de novilhas em pastagem de capim Tifton 85 suplementadas com aditivos à base de própolis ou monensina sódica.

\begin{tabular}{lcccccc}
\hline Parâmetros & \multicolumn{3}{c}{ Tratamento } & Média & EPM & P \\
\cline { 2 - 4 } & AAD & PRO & MON & & & \\
\hline Peso corporal inicial $(\mathrm{kg})$ & 304,89 & 307,39 & 304,56 & 305,61 & 2,02 & $0,05^{\text {ns }}$ \\
Peso corporal final $(\mathrm{kg})$ & 347,57 & 356,06 & 349,22 & 350,98 & 2,48 & 0,348 \\
Ganho de peso corporal $(\mathrm{kg})$ & & & & & & \\
28 dias & $15,72 \mathrm{~b}$ & $22,72 \mathrm{a}$ & $19,83 \mathrm{a}$ & 19,43 & 0,67 & 0,001 \\
56 dias & $26,72 \mathrm{~b}$ & $31,89 \mathrm{a}$ & $29,39 \mathrm{ab}$ & 29,33 & 0,83 & 0,050 \\
85 dias & $42,78 \mathrm{a}$ & $48,67 \mathrm{a}$ & $44,67 \mathrm{a}$ & 45,37 & 1,24 & 0,154 \\
Ganho médio diário $\left(\mathrm{kg} \mathrm{dia}^{-1}\right)$ & & & & & & \\
28 dias & $0,562 \mathrm{~b}$ & $0,812 \mathrm{a}$ & $0,708 \mathrm{a}$ & 0,694 & 0,02 & 0,001 \\
56 dias & $0,477 \mathrm{~b}$ & $0,569 \mathrm{a}$ & $0,524 \mathrm{ab}$ & 0,524 & 0,01 & 0,050 \\
85 dias & $0,503 \mathrm{a}$ & $0,573 \mathrm{a}$ & $0,525 \mathrm{a}$ & 0,534 & 0,01 & 0,154 \\
\hline
\end{tabular}

AAD: ausência de aditivo; PRO: própolis; MON: monensina sódica. Médias seguidas de diferentes letras na linha diferem $(\mathrm{p}<0,05)$ pelo teste Tukey.

Fonte: Elaboração dos autores.

Para os primeiros 28 dias antes do início do ensaio de desempenho animal, ou seja, durante o período de adaptação das novilhas ao pasto e suplemento (mês de dezembro), os piquetes apresentaram baixa carga animal por hectare, a fim de garantir boa disponibilidade de forragem aos animais e eliminar a possibilidade de ganho compensatório no período experimental. Desta forma, a massa de forragem ( $\mathrm{kg}$ de $\mathrm{MS} \mathrm{ha}^{-1}$ ) no mês de janeiro (Tabela 3 ) foi superior aos demais meses de avaliação com valor de $3.592 \mathrm{~kg}$ de MS ha-1.

Foi utilizado o método de "Put and Take" para manter uma disponibilidade adequada e equilibrada de pastagem, segundo recomendações de Mott e Lucas (1952). A determinação da disponibilidade da forragem ou resíduo de matéria seca (RMS) foi realizada nos três piquetes utilizando o método de dupla amostragem (WILM; COSTELLO; KLIMPPLE, 1944) nos seguintes dias 27 de dezembro (período de adaptação); 24 de janeiro; 20 de fevereiro e 21 de março. Em cada piquete foram cortadas, ao nível do solo, doze amostras de $0,56 \mathrm{~m}^{2}$, pesadas e secas em estufa com ventilação forçada a $55^{\circ} \mathrm{C}$, por 72 horas para os meses de janeiro, fevereiro e março. Antes do corte, foi estimada visualmente a produção de matéria seca da amostra. Além das amostras cortadas, foram realizadas mais 48 avaliações visuais. Utilizando-se os valores das amostras cortadas e estimadas visualmente foi calculada a produção de matéria seca em $\mathrm{kg} \mathrm{ha}^{-1}$ pela equação proposta por Gardner (1986).

As amostras obtidas na dupla amostragem foram compostas proporcionalmente, formando três amostras (repetições) por piquete e por mês. Em seguida as amostras do capim Tifton 85 foram separadas em seus componentes estruturais: lâmina foliar (LF); bainha + colmo verde (BC); e material morto (MM), dos quais se obteve o peso seco e percentual individual. Foi determinada a produção dos componentes estruturais por área, multiplicando o percentual individual pela disponibilidade de forragem em cada mês de coleta. 
Tabela 3. Disponibilidade da massa de forragem ( $\mathrm{kg}$ de $\left.\mathrm{MS} \mathrm{ha}^{-1}\right)$ da planta inteira (PI), lâmina foliar verde (LF), bainha + colmo verde $(\mathrm{BC})$, material morto $(\mathrm{MM})$ e a relação lâmina foliar bainha ${ }^{-1}+$ colmo verde $\left(\mathrm{LF} \mathrm{BC}^{-1}\right)$, nos diferentes meses de avaliação.

\begin{tabular}{|c|c|c|c|c|c|}
\hline \multirow[t]{2}{*}{ Meses } & \multicolumn{5}{|c|}{ Componente da Planta (Kg de MS/ha) } \\
\hline & PI & LF & $\mathrm{BC}$ & $\mathrm{MM}$ & $\mathrm{LF} \mathrm{BC}^{-1}$ \\
\hline \multicolumn{6}{|l|}{ Janeiro $^{1}$} \\
\hline Ausência de aditivo - AAD & 3.311 & 500,60 & 1434,47 & 1374,37 & 0,34 \\
\hline Própolis - PRO & 3.691 & 594,42 & 1698,43 & 1398,66 & 0,34 \\
\hline Monensina - MON & 3.774 & 610,41 & 1675,11 & 1488,80 & 0,35 \\
\hline Média & $3.592 \mathrm{a}$ & $\begin{array}{l}568,48 \text { a } \\
\text { Fevereiro }^{1}\end{array}$ & $1602,67 \mathrm{a}$ & $1420,61 \mathrm{a}$ & $0,35 \mathrm{~b}$ \\
\hline Ausência de aditivo - AAD & 3.069 & 427,50 & 1291,23 & 1350,32 & 0,33 \\
\hline Própolis - PRO & 3.123 & 446,52 & 1408,02 & 1268,74 & 0,32 \\
\hline Monensina - MON & 3.212 & 460,54 & 1443,65 & 1308,14 & 0,32 \\
\hline $\begin{array}{l}\text { Média } \\
\text { Março }^{1}\end{array}$ & $3.134 \mathrm{~b}$ & $444,85 \mathrm{~b}$ & $1380,97 \mathrm{ab}$ & $1309,07 \mathrm{ab}$ & $0,33 \mathrm{~b}$ \\
\hline Ausência de aditivo - AAD & 2.904 & 497,58 & 1141,12 & 1265,36 & 0,44 \\
\hline Própolis - PRO & 3.045 & 519,29 & 1238,72 & 1287,11 & 0,42 \\
\hline Monensina - MON & 2.990 & 451,22 & 1217,17 & 1321,72 & 0,37 \\
\hline Média & $2.979 \mathrm{~b}$ & $489,36 \mathrm{ab}$ & $1199,00 \mathrm{~b}$ & $1291,40 \mathrm{~b}$ & $0,41 \mathrm{a}$ \\
\hline EPM & 51,40 & 13,61 & 33,52 & 15,03 & 0,01 \\
\hline $\mathrm{P}$ & 0,006 & 0,026 & 0,007 & 0,025 & 0,006 \\
\hline
\end{tabular}

${ }^{1}$ intervalo de avaliação de 28 dias cada; EPM: erro-padrão da média. Médias, na coluna, seguidas de diferentes letras diferem $(\mathrm{p}<0,05)$ pelo teste Tukey.

Fonte: Elaboração dos autores.

Após a separação, as amostras de forragem foram secas em estuda de ventilação forçada a $55^{\circ} \mathrm{C}$ por 72 horas e moídas em moinho tipo faca com peneira apresentando crivos de um $\mathrm{mm}$, para posteriores análises bromatológica. A disponibilidade da massa de forragem (MS ha-1) do capim Tifton 85 para a planta inteira, lamina foliar, bainha + colmo verde e material morto está demonstrado na Tabela 3. A composição bromatológica do capim Tifton 85 está demonstrada na Tabela 4. As análises dos nutrientes do capim Tifton 85 e grão de milho moído foram realizados segundo descrição de Silva e Queiroz (2002).

Para o ensaio de comportamento ingestivo foram utilizadas cinco novilhas Nelores dos diferentes tratamentos do ensaio de desempenho animal, as quais foram marcadas com numeração diferente no dorso com tinta apropriada além de terem recebido cabrestos de cor diferente para identificação das mesmas dentro dos piquetes durante a avaliação.

Durante a avaliação do comportamento ingestivo utilizou-se metodologia descrita por Martin e Batenson (1986), com observação direta, rota de amostragem focal e rota de coleta instantânea, utilizando-se intervalo amostral de 5 minutos.

O período total de avaliação do comportamento ingestivo das novilhas em pastagem suplementadas ou não com aditivos teve duração de 30 dias, sendo utilizados três períodos de coleta de dados (observações) com dois dias consecutivos em cada tratamento com intervalo de 12 dias entre os períodos de observações do comportamento ingestivo. Desta maneira, foi utilizada a média das seis coletas de dados para o comportamento ingestivo, as quais ocorreram nas seguintes datas 01; 02; 15 e 16 de fevereiro e nos dias 01 e 02 de março. 
Tabela 4. Composição bromatológica dos componentes estruturais do capim Tifton 85 nos meses avaliados.

\begin{tabular}{|c|c|c|c|c|c|c|}
\hline \multirow[t]{2}{*}{ Análises } & \multicolumn{3}{|c|}{$\begin{array}{c}\text { Componentes estruturais }\left(\mathrm{g} \mathrm{kg}^{-1}\right) \text { nos diferentes meses de } \\
\text { avaliação }\end{array}$} & \multirow[t]{2}{*}{ Média } & \multirow[t]{2}{*}{ EPM } & \multirow[t]{2}{*}{$\mathrm{P}$} \\
\hline & Janeiro $^{1}$ & Fevereiro $^{2}$ & Março $^{3}$ & & & \\
\hline \multicolumn{7}{|c|}{ Lâmina foliar } \\
\hline MS & $341,3 \mathrm{~b}$ & $388,6 \mathrm{ab}$ & $395,8 \mathrm{a}$ & 375,2 & 6,75 & 0,032 \\
\hline MO & $920,2 \mathrm{a}$ & $915,8 \mathrm{a}$ & $906,1 \mathrm{~b}$ & 914,0 & 0,87 & 0,001 \\
\hline PB & 171,9 a & 174,8 a & $176,4 \mathrm{a}$ & 174,4 & 3,01 & $0,08^{\text {ns }}$ \\
\hline FDN & 696,2 a & $672,4 \mathrm{~b}$ & $659,6 \mathrm{~b}$ & 676,0 & 2,91 & 0,005 \\
\hline NDT & $547,5 \mathrm{~b}$ & $557,4 \mathrm{a}$ & $562,8 \mathrm{a}$ & 555,9 & 1,21 & 0,005 \\
\hline \multicolumn{7}{|c|}{ Bainha + colmo verde } \\
\hline MS & $246,6 \mathrm{~b}$ & $278,9 \mathrm{ab}$ & $286,7 \mathrm{a}$ & 370,8 & 4,91 & 0,034 \\
\hline MO & $911,0 \mathrm{~b}$ & $915,3 \mathrm{ab}$ & $920,1 \mathrm{a}$ & 915,5 & 0,84 & 0,012 \\
\hline PB & $83,8 \mathrm{a}$ & $79,0 \mathrm{a}$ & $69,4 \mathrm{a}$ & 77,4 & 2,46 & 0,128 \\
\hline FDN & $742,5 \mathrm{a}$ & $734,2 \mathrm{a}$ & $751,1 \mathrm{a}$ & 742,6 & 2,64 & 0,103 \\
\hline NDT & $528,2 \mathrm{a}$ & $531,7 \mathrm{a}$ & 524,6 a & 528,2 & 1,10 & 0,104 \\
\hline \multicolumn{7}{|c|}{ Material morto } \\
\hline MS & $558,8 \mathrm{~b}$ & $658,1 \mathrm{a}$ & 694,8 a & 637,2 & 13,04 & 0,013 \\
\hline MO & $911,8 \mathrm{~b}$ & $921,7 \mathrm{~b}$ & 936,8 a & 923,4 & 1,65 & 0,002 \\
\hline
\end{tabular}

${ }^{1}$ intervalo de avaliação de 28 dias cada; MS: matéria seca; MO: matéria orgânica; PB: proteína bruta; FDN: fibra em detergente neutro; NDT: nutrientes digestíveis totais; EPM: erro-padrão da média. Médias, na linha, seguidas de diferentes letras diferem $(\mathrm{p}<0,05)$ pelo teste Tukey.

Fonte: Elaboração dos autores.

A avaliação do comportamento ingestivo foi de 12 horas por dia, o qual teve inicio as 7 horas e termino as 19 horas, o intervalo utilizado entre cada observação foi de 5 minutos (MARTIN; BATENSON, 1986). Para a coleta de dados das variáveis do comportamento ingestivo foi utilizada uma planilha animal ${ }^{-1}$ tratamento $^{-1}$, na qual foi descriminado nas colunas as diferentes variáveis de comportamento e nas linhas foram descritos os horários de coleta com intervalo de cinco minutos, após o termino da sexta coleta de dados estes foram tabulados em planilha eletrônica.

Os comportamentos (atividades) observados nas novilhas em pastejo foram: pastejo (PAS), ruminação deitado (RDE) ruminação em pé (RPE), ruminação (RU), ócio deitado (ODE), ócio em pé (OPE), ócio (OC), andando (AND), consumo de suplemento e água (CSA), postura em pé (PE) e postura deitado (DE) essas duas ultimas estão relacionadas as atividades que não se enquadram com nenhuma outra descrita anteriormente (ex: brincando, coçando, consumo de sal mineral e etc.), os quais foram mensurados durante doze horas por dia no período das 7 horas às 19 horas. O período total de avaliação do comportamento ingestivo dia $^{-1}$ foi dividido em três, onde o período um teve duração das 7horas às 11 horas, o período dois das 11 horas às 15 horas e o terceiro período das 15 horas às 19 horas.

O tempo total de cada atividade observada nos diferentes períodos foi obtido somando o total de vezes que cada novilha estava em determinado estado seguindo as recomendações de Souza (2007).

Foram coletados os dados de temperatura do ar, velocidade do vento e umidade relativa do ar a cada hora durante o período de avaliação do comportamento ingestivo por meio de um termoanemômetro, marca Kestel 3000 . Além disso, foi calculado o índice de temperatura e umidade (ITU), descrito por Silva (2000), como demostrado na Tabela 5. 
Tabela 5. Variáveis meteorológicas e de conforto térmico. Médias de temperatura do ar, umidade relativa do ar, velocidade do vento e índice de temperatura e umidade (ITU) do mês de fevereiro de 2011.

\begin{tabular}{lllll}
\hline Variáveis & \multicolumn{2}{c}{ Períodos de avaliação do comportamento ingestivo } & Período total \\
\cline { 2 - 4 } & $7 \mathrm{~h}$ às $11 \mathrm{~h}$ & $11 \mathrm{~h}$ às $15 \mathrm{~h}$ & $15 \mathrm{~h}$ às $19 \mathrm{~h}$ & (12 horas) \\
\hline Temperatura do $\operatorname{ar}\left({ }^{\circ} \mathrm{C}\right)$ & 22,72 & 27,04 & 27,91 & 25,89 \\
Umidade relativa do $\operatorname{ar}(\%)$ & 88,88 & 69,69 & 66,90 & 75,15 \\
Velocidade do vento $\left(\mathrm{m} \mathrm{s}^{-1}\right)$ & 2,36 & 4,00 & 4,23 & 3,62 \\
ITU & 71,79 & 76,04 & 76,95 & 74,93 \\
\hline
\end{tabular}

Fonte: Elaboração dos autores.

O delineamento experimental empregado para o ensaio de desempenho animal foi inteiramente casualizado com três tratamentos e dezoito repetições. Os dados do desempenho animal foram submetidos à análise de variância considerando nível de significância de $5 \%$ e as médias foram comparadas, pelo teste de Tukey a 5\% de probabilidade. Os dados de ganho médio diário foram analisados com o seguinte modelo estatístico: $Y_{i j k}=\mu+T_{i}+P_{j}+T P_{i j}+e_{i j k ;}$ m que: $Y_{i j k}=$ observação referente ao indivíduo $k$ no tratamento $i$ no mês $j ; \mu=$ constante geral; $T_{i}=$ efeito do tratamento $i$ variando de 1 a $3 ; P_{j}=$ efeito do mês $j$ variando de 1 a $3 ; T P_{i j}$ $=$ efeito da interação entre tratamento $i$ no mês $j ; e_{i j k}$ $=$ erro aleatório associado a cada observação.

Os dados de produção de forragem foram analisados seguindo o modelo estatístico: $Y_{i j}=\mu+P_{i}$ $+e_{i j, e}$ m que: $Y_{i j k}=$ observação referente à variável $j$ no mês $i ; \mu=$ constante geral; $P_{j}=$ efeito do mês $j$ variando de 1 a $3 ; e_{i j}=$ erro aleatório associado a cada observação.

Para o ensaio do comportamento ingestivo foi utilizado delineamento em fatorial $3 \times 3$ (três tratamentos e três períodos de avaliação do comportamento: 7horas às 11horas; 11horas às 15 horas e 15 horas às 19 horas) com cinco repetições por tratamento. A estatística das variáveis estudadas (comportamento ingestivo) foi interpretada no Sistema de Melhoramento Genético e Estatístico (SAEG) por meio de análise de variância (RIBEIRO JÚNIOR; MELO, 2008). As diferenças obtidas para as variáveis estudadas (comportamento ingestivo) em novilhas a pasto suplementadas com aditivos foram avaliadas por meio de teste de Tukey considerando 5\% de significância.

\section{Resultados e Discussão}

A suplementação energético-mineral com aditivo a base de própolis (PRO) em novilhas a pasto propiciou maior $(\mathrm{P}<0,05)$ GMD no mês de fevereiro $\left(0,569 \mathrm{~kg} \mathrm{dia}^{-1}\right)$ em relação ao tratamento com ausência de aditivo - AAD $\left(0,477 \mathrm{~kg} \mathrm{dia}^{-1}\right)$ e semelhante ao tratamento com monensina - MON $\left(0,524 \mathrm{~kg} \mathrm{dia}^{-1}\right)$ que por sua vez não diferiu do AAD, no período de 54 dias (janeiro e fevereiro de 2011), Tabela 2. Para 85 dias de avaliação do desempenho das novilhas a pasto não houve $(\mathrm{P}>0,05)$ efeito dos aditivos no desempenho animal, provavelmente este fato pode ter ocorrido devido à adaptação das bactérias ruminais aos aditivos.

Para o mês de fevereiro no qual ocorreu a avaliação do comportamento ingestivo das novilhas a pasto foi observado uma disponibilidade do capim Tifton 85 de $3.134 \mathrm{~kg}$ de MS ha-1 (Tabela 3), a qual está acima do preconizado por Corsi e Martha Junior (1998) para gramíneas do gênero Cynodon de 2.500 $\mathrm{kg}$ de $\mathrm{MS} \mathrm{ha}^{-1}$ para pastagens bem manejadas.

Com relação aos teores de fibra em detergente neutro (FDN) encontrados na lâmina foliar (Tabela 4) foi observada diferença $(\mathrm{P}<0,01)$ nos meses avaliados. O teor de FDN da lâmina foliar reduziu de 696,2 $\mathrm{g} \mathrm{kg}^{-1}$ em janeiro para 672,4 e 659,6 $\mathrm{g} \mathrm{kg}^{-1}$ no mês de fevereiro e março, respectivamente. $\mathrm{Na}$ bainha + colmo verde não houve diferença no teor de FDN $(\mathrm{P}>0,05)$ entre os meses com média de 742,6 
$\mathrm{g} \mathrm{kg}^{-1}$. Estes valores estão próximos aos obtidos por Poli, Monteiro e Barros (2008) para capim Tifton 85 na mesma época de avaliação, os autores relataram valores de fibra em detergente neutro variando de 665,1 a $712,0 \mathrm{~g} \mathrm{~kg}^{-1}$. Não houve diferença $(\mathrm{P}>0,05)$ para o teor de PB da lamina foliar do capim Tifton 85 entre os meses avaliados, e com uma média de $174,4 \mathrm{~g} \mathrm{~kg}^{-1}$.

A descrição das variáveis meteorológicas, bem como, do índice de temperatura e umidade (ITU) dos dias de observação do comportamento ingestivo estão descritas na Tabela 5. Vale destacar que o período observado não apresentou um ambiente climático desconfortável, com temperaturas dentro da zona de termoneutralidade para bovinos zebuínos, bem como, com o ITU, variou de brando a moderado (72 a 78), conforme classificação de Hahn e Mader (1997).

Vale destacar que o tempo utilizado para a atividade de $\mathrm{RDE}$ foi maior $(\mathrm{P}<0,05)$ para as novilhas do tratamento com PRO em relação ao $\mathrm{AAD}$, no primeiro período de avaliação do dia (7horas às 11horas), Tabela 6. O maior tempo de ruminação nesse tratamento pode estar relacionado à condição de conforto promovida por este tratamento, devido a mudança do ambiente de fermentação ruminal, o qual provavelmente propiciou maior atividade bacteriana levando a maior tempo de ruminação e produção de saliva para manter o $\mathrm{pH}$ ruminal. Apesar da ação da própolis estar focada na seleção de cepas de bactérias, podem ocorrer ações sinérgicas resultando em favorecimento do bemestar dos animais que consomem esse produto, promovendo assim um maior tempo de ruminação na postura deitado.

O tempo expresso em minutos para a atividade de consumo de suplemento e água (CSA) foi maior $(\mathrm{P}<0,05)$ para tratamento $\mathrm{AAD}(3,29 \mathrm{~min})$, no terceiro período de avaliação do dia (15horas às 19horas), Tabela 6, quando comparado com aos tratamentos com PRO (1,46min) e MON (1,08min). Este fato sugere que os aditivos (PRO e MON) misturados ao suplemento energético-mineral provavelmente modificaram a qualidade organoléptica do suplemento influenciando na aceitabilidade do mesmo pelas novilhas suplementadas a pasto, com um consumo mais rápido do suplemento nesses tratamentos. Entretanto, é importante avaliar o aspecto metodológico da coleta da informação. A ingestão de água, bem como, o consumo de concentrado são ações que ocorrem com pouca duração do comportamento, sendo assim, a rota de coleta instantânea (com intervalo amostral de cinco minutos) pode não ser a mais adequada para tal procedimento, sendo a rota de coleta contínua a mais usual para esse procedimento.

Para todas as atividades dos comportamentos ingestivo foram observados o efeito de período de avaliação durante o dia $(\mathrm{P}<0,05)$ sobre os tempos despendidos nessas atividades (Tabela 6). As atividades de PAS e CSA foram $(\mathrm{P}<0,05)$ maiores no terceiro período de avaliação do dia em relação ao primeiro período de avaliação, isso pode ter sido influenciado pelo fornecimento do suplemento às 17 horas. Além disso, como o ambiente climático se apresentou com características termonêutras para bovinos da raça Nelore, pode ter ocorrido uma preferência para o pastejo nesse período do dia. Outro fator que pode ter influenciado essa resposta foi a grande quantidade de umidade retida na pastagem, observada no período da manhã devido as chuvas que ocorreram antes das 6horas da manhã durante o período de avaliação, este fato pode ser confirmado na Tabela 5, que pode ser observado alta umidade relativa do ar $(88,88 \%)$ para o primeiro período de avaliação do dia. Isto pode ter interferido no comportamento ingestivo das novilhas, uma vez que os animais esperavam a temperatura do ar subir e a pastagem secar para começarem as diferentes atividades (pastejo, andar e outras). 
Tabela 6. Tempo (min animal ${ }^{-1}$ hora $^{-1}$ ) utilizado para diferentes atividades do comportamento ingestivo de novilhas recebendo suplemento energético-mineral sem aditivo (AAD), com própolis (PRO) ou monensina sódica (MON) durante 12 horas por dia (7horas às 19horas) divididas em três períodos de avaliação.

\begin{tabular}{|c|c|c|c|c|c|c|}
\hline \multirow[t]{2}{*}{ Comportamento } & \multirow[t]{2}{*}{ Período } & \multicolumn{3}{|c|}{ Tratamento } & \multirow[t]{2}{*}{ Media } & \multirow[t]{2}{*}{$\mathrm{DP}$} \\
\hline & & $\mathrm{AAD}$ & PRO & MON & & \\
\hline \multirow{4}{*}{ PAS } & $7 \mathrm{~h}$ às $11 \mathrm{~h}$ & $25,67 \mathrm{a}$ & $21,08 \mathrm{a}$ & $27,63 \mathrm{a}$ & $24,79 \mathrm{~B}$ & 21,13 \\
\hline & $11 \mathrm{~h}$ às $15 \mathrm{~h}$ & $37,71 \mathrm{a}$ & 39,96 a & 39,96 a & $39,21 \mathrm{AB}$ & 18,98 \\
\hline & $15 \mathrm{~h}$ às $19 \mathrm{~h}$ & $45,75 \mathrm{a}$ & $45,71 \mathrm{a}$ & $47,04 \mathrm{a}$ & $46,17 \mathrm{~A}$ & 14,01 \\
\hline & média & 36,38 & 35,58 & 38,21 & 36,72 & \\
\hline \multirow{4}{*}{ RU } & $7 \mathrm{~h}$ às $11 \mathrm{~h}$ & $15,75 \mathrm{a}$ & $17,79 \mathrm{a}$ & $14,33 \mathrm{a}$ & $15,96 \mathrm{~A}$ & 14,22 \\
\hline & $11 \mathrm{~h}$ às $15 \mathrm{~h}$ & $10,54 \mathrm{a}$ & $9,21 \mathrm{a}$ & $9,92 \mathrm{a}$ & $9,89 \mathrm{AB}$ & 13,17 \\
\hline & $15 \mathrm{~h}$ às $19 \mathrm{~h}$ & $6,00 \mathrm{a}$ & $6,46 \mathrm{a}$ & $5,13 \mathrm{a}$ & $5,86 \mathrm{~B}$ & 11,08 \\
\hline & média & 10,76 & 11,15 & 9,79 & 10,57 & \\
\hline \multirow{4}{*}{ RDE } & 7 às $11 \mathrm{~h}$ & $10,04 \mathrm{~b}$ & $12,50 \mathrm{a}$ & $10,71 \mathrm{ab}$ & $11,08 \mathrm{~A}$ & 12,50 \\
\hline & 11 às $15 \mathrm{~h}$ & $10,13 \mathrm{a}$ & $8,42 \mathrm{a}$ & $9,42 \mathrm{a}$ & $9,32 \mathrm{AB}$ & 12,85 \\
\hline & 15 às $19 \mathrm{~h}$ & $5,33 \mathrm{a}$ & $5,21 \mathrm{a}$ & $4,88 \mathrm{a}$ & $5,14 \mathrm{~B}$ & 10,20 \\
\hline & média & 8,50 & 8,71 & 8,33 & 8,51 & \\
\hline \multirow{4}{*}{ RPE } & $7 \mathrm{~h}$ às $11 \mathrm{~h}$ & $5,71 \mathrm{a}$ & $5,29 \mathrm{a}$ & $3,63 \mathrm{~b}$ & $4,88 \mathrm{~A}$ & 8,78 \\
\hline & $11 \mathrm{~h}$ às $15 \mathrm{~h}$ & $0,42 \mathrm{a}$ & $0,79 \mathrm{a}$ & $0,50 \mathrm{a}$ & $0,57 \mathrm{~B}$ & 2,34 \\
\hline & $15 \mathrm{~h}$ às $19 \mathrm{~h}$ & $0,67 \mathrm{ab}$ & $1,25 \mathrm{a}$ & $0,25 \mathrm{~b}$ & $0,72 \mathrm{~B}$ & 3,38 \\
\hline & média & 2,26 & 2,44 & 1,46 & 2,06 & \\
\hline \multirow{4}{*}{ CSA } & $7 \mathrm{~h}$ às $11 \mathrm{~h}$ & $0,63 \mathrm{a}$ & $0,25 \mathrm{a}$ & $0,04 \mathrm{a}$ & $0,31 \mathrm{~B}$ & 1,31 \\
\hline & $11 \mathrm{~h}$ às $15 \mathrm{~h}$ & $0,38 \mathrm{a}$ & $0,83 \mathrm{a}$ & $0,96 \mathrm{a}$ & $0,72 \mathrm{~B}$ & 1,80 \\
\hline & $15 \mathrm{~h}$ às $19 \mathrm{~h}$ & $3,29 \mathrm{a}$ & $1,46 \mathrm{~b}$ & $1,08 \mathrm{~b}$ & $1,94 \mathrm{~A}$ & 3,96 \\
\hline & média & 1,43 & 0,85 & 0,69 & 0,99 & \\
\hline
\end{tabular}

PAS: pastejo; RU: ruminando; RDE: ruminação deitado; RPE: ruminação em pé; e CSA: consumo de suplemento e água. Letras maiúsculas representam diferença pelo teste de Tukey $(\mathrm{p}<0,05)$ entre os períodos e letras minúsculas representam diferença pelo teste de Tukey $(\mathrm{p}<0,05)$ para os tratamentos dentro dos períodos. DP: desvio padrão.

Fonte: Elaboração dos autores.

Pode ser observado que o tempo utilizado no primeiro período do dia de avaliação do comportamento ingestivo para as atividades RU, RDE e RPE (Tabela 6) foi superior $(\mathrm{P}<0,05)$ ao terceiro período do dia, indicando que as novilhas começavam a atividade de pastejo com o aumento da temperatura ambiente e redução da umidade retida no capim Tifton 85 .

Estudo realizado por Souza (2007), para avaliar o comportamento ingestivo de novilhas suplementadas em pastejo com Uruchloa brizantha (cv. Marandu) demonstrou que independente do tratamento (sal comum, suplemetação com proteinado e suplementação com proteinado + monensina sódica), as novilhas concentraram o pastejo nas primeiras horas do dia e ao entardecer com 37,5 minutos hora ${ }^{-1}$ animal $^{-1} \mathrm{dia}^{-1}$, valor próximo ao observado no presente estudo de 36,7 minutos hora $^{-1}$ animal $^{-1} 12$ horas de avaliação ${ }^{-1}$.

Os registros dos comportamentos de rotina (andando, ócio, ócio deitado, ócio em pé, postura em pé e postura deitado) das novilhas a pasto podem ser observados na Tabela 7. Para a atividade ócio (OC) e postura deitado (DE), foi observado maior $(\mathrm{P}<0,05)$ tempo para as novilhas do tratamento com PRO no primeiro período de avaliação do dia em relação aos demais tratamentos (AAD e MON). Normalmente, bovinos que apresentam menor atividade, estando em condição de pastejo, demonstram estar em condições mais favoráveis de bem-estar, ou seja, suas necessidades fisiológicas se encontram em equilíbrio homeostático fazendo com que o organismo não demonstre reações de busca de recursos para suprir possíveis deficiências ou carências orgânicas. 
Tabela 7. Tempo (min animal-1 hora $^{-1}$ ) utilizado para diferentes atividades do comportamento ingestivo de novilhas recebendo suplemento energético-mineral sem aditivo (AAD), com própolis (PRO) ou monensina sódica (MON) durante 12 horas por dia (7horas às 19horas) divididas em três períodos de avaliação.

\begin{tabular}{|c|c|c|c|c|c|c|}
\hline \multirow[t]{2}{*}{ Comportamento } & \multirow[t]{2}{*}{ Período } & \multicolumn{3}{|c|}{ Tratamento } & \multirow[t]{2}{*}{ Média } & \multirow[t]{2}{*}{ DP } \\
\hline & & AAD & PRO & DP & & \\
\hline \multirow{4}{*}{ AND } & $7 \mathrm{~h}$ às $11 \mathrm{~h}$ & $0,21 \mathrm{a}$ & $0,50 \mathrm{a}$ & $1,33 \mathrm{a}$ & $0,68 \mathrm{~A}$ & 1,91 \\
\hline & $11 \mathrm{~h}$ às $15 \mathrm{~h}$ & $0,71 \mathrm{~b}$ & $1,92 \mathrm{a}$ & $1,63 \mathrm{a}$ & $1,42 \mathrm{~A}$ & 2,49 \\
\hline & $15 \mathrm{~h}$ às $19 \mathrm{~h}$ & $2,17 \mathrm{a}$ & $1,54 \mathrm{a}$ & $2,13 \mathrm{a}$ & $1,94 \mathrm{~A}$ & 3,10 \\
\hline & média & 1,03 & 1,32 & 1,69 & 1,35 & \\
\hline \multirow{4}{*}{$\mathrm{OC}$} & $7 \mathrm{~h}$ às $11 \mathrm{~h}$ & $17,96 \mathrm{~b}$ & $20,88 \mathrm{a}$ & $18,00 \mathrm{~b}$ & $18,94 \mathrm{~A}$ & 14,67 \\
\hline & $11 \mathrm{~h}$ às $15 \mathrm{~h}$ & $11,38 \mathrm{a}$ & $10,00 \mathrm{a}$ & $9,17 \mathrm{a}$ & $10,18 \mathrm{AB}$ & 9,44 \\
\hline & $15 \mathrm{~h}$ às $19 \mathrm{~h}$ & $4,96 \mathrm{~b}$ & $6,38 \mathrm{ab}$ & $6,75 \mathrm{a}$ & $6,03 \mathrm{~B}$ & 6,37 \\
\hline & média & 11,43 & 12,42 & 11,31 & 11,72 & \\
\hline \multirow{4}{*}{ OPE } & $7 \mathrm{~h}$ às $11 \mathrm{~h}$ & $8,29 \mathrm{ab}$ & $7,63 \mathrm{~b}$ & $8,36 \mathrm{a}$ & $8,09 \mathrm{~A}$ & 11,88 \\
\hline & $11 \mathrm{~h}$ às $15 \mathrm{~h}$ & $3,07 \mathrm{a}$ & $2,67 \mathrm{a}$ & $2,54 \mathrm{a}$ & $2,76 \mathrm{~B}$ & 4,55 \\
\hline & $15 \mathrm{~h}$ às $19 \mathrm{~h}$ & $1,50 \mathrm{~b}$ & $2,75 \mathrm{a}$ & $3,25 \mathrm{a}$ & $2,50 \mathrm{~B}$ & 3,95 \\
\hline & média & 4,29 & 4,35 & 4,71 & 4,45 & \\
\hline \multirow{4}{*}{ ODE } & $7 \mathrm{~h}$ às $11 \mathrm{~h}$ & $9,46 \mathrm{a}$ & $12,75 \mathrm{a}$ & $8,38 \mathrm{a}$ & $10,19 \mathrm{~A}$ & 11,92 \\
\hline & $11 \mathrm{~h}$ às $15 \mathrm{~h}$ & $7,63 \mathrm{a}$ & $5,42 \mathrm{~b}$ & $5,00 \mathrm{~b}$ & 6,01 A & 8,94 \\
\hline & $15 \mathrm{~h}$ às $19 \mathrm{~h}$ & $1,31 \mathrm{a}$ & $2,10 \mathrm{a}$ & $1,38 \mathrm{a}$ & $1,60 \mathrm{~B}$ & 4,45 \\
\hline & média & 6,16 & 6,77 & 4,92 & 5,95 & \\
\hline \multirow{4}{*}{ PE } & $7 \mathrm{~h}$ às $11 \mathrm{~h}$ & $31,58 \mathrm{a}$ & $26,88 \mathrm{a}$ & $32,58 \mathrm{a}$ & $30,35 \mathrm{~A}$ & 19,70 \\
\hline & $11 \mathrm{~h}$ às $15 \mathrm{~h}$ & $38,83 \mathrm{a}$ & $42,67 \mathrm{a}$ & $42,08 \mathrm{a}$ & $41,19 \mathrm{~A}$ & 19,02 \\
\hline & $15 \mathrm{~h}$ às $19 \mathrm{~h}$ & 48,58 a & $48,50 \mathrm{a}$ & $49,42 \mathrm{a}$ & $48,83 \mathrm{~B}$ & 13,09 \\
\hline & média & 39,67 & 39,35 & 41,36 & 4,45 & \\
\hline \multirow{4}{*}{$\mathrm{DE}$} & $7 \mathrm{~h}$ às $11 \mathrm{~h}$ & $19,50 \mathrm{~b}$ & $25,25 \mathrm{a}$ & $19,08 \mathrm{~b}$ & $21,28 \mathrm{~A}$ & 18,93 \\
\hline & $11 \mathrm{~h}$ às $15 \mathrm{~h}$ & $17,75 \mathrm{a}$ & 13,83 a & $14,42 \mathrm{a}$ & $15,33 \mathrm{~A}$ & 19,02 \\
\hline & $15 \mathrm{~h}$ às $19 \mathrm{~h}$ & 6,63 a & 7,29 a & 6,25 a & $6,72 \mathrm{~B}$ & 12,25 \\
\hline & média & 14,63 & 15,46 & 13,25 & 14,44 & \\
\hline
\end{tabular}

AND: andando; OC: ócio; ODE: ócio deitado, OPE: ócio em pé; PE: postura em pé; DE: postura deitado. Letras maiúsculas representam diferença pelo teste de Tukey $(\mathrm{p}<0,05)$ entre os período e letras minúsculas representam diferença pelo teste de Tukey $(\mathrm{p}<0,05)$ para os tratamentos dentro dos períodos. DP: desvio padrão.

Fonte: Elaboração dos autores.

Estudos realizados por Faria et al. (2011) indicaram que os bovinos buscam seu maior conforto quando as condições do ambiente são favoráveis, no caso do presente estudo o excesso de umidade relativa do ar no período da manhã (Tabela 5) pode ter contribuído para o maior tempo utilizado para a atividade de $\mathrm{OC}$ e DE.

Para as atividades de ócio, ócio em pé, ócio deitado, postura em pé e postura deitado (Tabela 7) das novilhas a pasto foi observado que o primeiro período de avaliação do dia influenciou no maior $(\mathrm{P}<0,05)$ tempo utilizado para essas atividades em relação ao segundo período de avaliação do dia, indicando que as novilhas iniciavam as atividades físicas de maior dispêndio energético (pastejo), com o aumento da temperatura do ar (ambiente) e consequente redução da umidade relativa do ar. Outro fato que pode ter contribuído para o maior tempo utilizado para as atividades de OC, OPE, ODE, PE e DE no período das 7horas às 11 horas pode estar correlacionado com a oferta do aditivo que ocorreu no final da tarde (17horas), o qual pode ter propiciado melhora no ambiente ruminal possibilitando maior tempo utilizado pelas novilhas para o pastejo e consequentemente reduziu as outras atividades do comportamento ingestivo das novilhas no final da tarde (15horas às 19horas). 


\section{Conclusões}

Apesar de não ter sido observado grandes diferenças nas atividades de comportamento ingestivo, bem como nos de rotina, conclui-se que a utilização de aditivo a base de própolis possibilita a substituição da monensina sódica para novilhas mantidas a pasto sem alterar o comportamento ingestivo, assim a introdução de produto natural à base de própolis na alimentação de bovinos pode ser uma alternativa para os produtores e ao mercado pecuário, uma vez que a monensina sódica está proibida em alguns países da União Europeia.

\section{Agradecimentos}

Ao Centro de Ensino Superior de Maringá (CESUMAR) por ter cedido o setor de bovinocultura de corte e os animais avaliados no presente estudo. Ao professor Dr. Emílio Fernandes Prohmann por ter apoiado e auxiliado no desenvolvimento desta pesquisa e a Universidade Estadual de Maringá - UEM por ter colaborado com os bolsistas de iniciação cientifica e alunos de pós-graduação em Zootecnia e demais infraestruturas utilizadas para a condução do presente estudo.

\section{Referências}

ALBRIGHT, J. L. Nutrition and feeding calves: feeding behaviour of dairy cattle. Journal of Dairy Science, Champaign, v. 76, n. 2, p. 485-498, 1993.

BANKOVA, V.; DYULGEROV, A.; POPOV, S. Propolis produced in Bulgaria and Mongolia: phenolic compounds and plant origin. Apidologie, Les Ulis Cedex, v. 23, n. 1, p. 79-85, 1992.

CARVALHO, S.; RODRIGUES, M. T.; BRANCO, R. H.; RODRIGUES, C. A. F. Comportamento ingestivo de cabras Alpinas em lactação alimentadas com dietas contendo diferentes níveis de fibra em detergente neutro proveniente de forragem. Revista Brasileira de Zootecnia, Viçosa, v. 35, n. 2, p. 562-568, 2006.

CORSI, M.; MARTHA JUNIOR, G. B. Manejo de pastagens para produção de carne e leite. In: SIMPÓSIO SOBRE MANEJO DA PASTAGEM, 15., 1998, Piracicaba. Palestras... Piracicaba: Fundação de Estudos Agrários Luiz de Queiroz, 1998, p. 296.
COSGROVE, G. P. Grazing behaviour and forage intake. In: SIMPÓSIO INTERNACIONAL SOBRE PRODUÇÃO ANIMAL EM PASTEJO, Viçosa, 1997. Anais... Viçosa: UFV, 1997, p. 59-80.

DAMASCENO, J. C.; BACARRI JUNIOR, F.; TARGA, L. A. Respostas comportamentais de vacas holandesas com acesso a sombra constante ou limitada. Pesquisa Agropecuária Brasileira, Brasília, v. 3, n. 34, p. 709-715, 1999.

FARIA, L. A. N.; BARBOSA, O. R.; ZEOULA, L. M.; AGUIAR, S. C.; PRADO, R. M.; BERTOLONI, D. A. Produto à base de própolis (LLOS) na dieta de bovinos inteiros confinados: comportamento animal e resposta sanguíneas. Acta Scientiarum. Animal Sciences, Maringá, v. 33, n. 1, p. 79-85, 2011.

FARINATTI, L. H.; POLI, C. H. A. C.; MONKS, P. L.; FISCHER, V.; CELLA JÚNIOR, A.; VARELA, M.; GABANA, G.; SONEGO, E.; CAMPOS, F. S. Comportamento ingestivo de vacas holandesas em sistemas de produção de leite a pasto na região da Campanha do Rio Grande do Sul. In: REUNIÃO ANUAL DA SOCIEDADE BRASILEIRA DE ZOOTECNIA, 41., 2004, Campo Grande. Anais... Campo Grande, 2004. CD-ROM.

FRANCO, S. L.; BUENO, J. H. F. Otimização de processo extrativo de própolis. Infarma, Brasília, v. 11, n. 11/12, p. 48-51, 1999.

FRASER, A. F. Comportamiento de los animales de la granja. Zaragoza: Acribia, 1980. 291 p.

FREITAS, J. A.; ANTONANGELO, R. P.; RIBEIRO, J. L.; JOSLIN, M.; NOGUEIRA, S. R. P.; SOUZA, J. C. Extrato etanoico de própolis na alimentação de vacas leiteiras. Revista Brasileira de Saúde e Produção Animal, Salvador, v. 10, n. 2, p. 333-343, 2009.

GARDNER, A. L. Técnicas de pesquisa em pastagem e aplicabilidade de resultados em sistema de produção. Brasília: IICA/EMBRAPA 3/4 CNPGL, 1986. 197 p.

GARY, L. A.; SHERRITT, G. W.; HALE, E. B. Behavior of Charolais cattle on pasture. Journal of Animal Science, Champaign, v. 30, n. 2, p. 303-306, 1970.

GREENWAY, W.; SCAYSBROOK, T.; WHATLEY, F. $\mathrm{R}$. The composition and plant origins of propolis: a report of work at Oxford. Bee World, London, v. 71, n. 3, p. 107-118, 1990.

HAHN, G. L.; MADER, T. L. Heat waves in relation to thermoregulation, feeding behavior and mortality of feedlot cattle. In: PROCEEDINGS OF THE INTERNATIONAL LIVESTOCK ENVIRONMENT SYMPOSIUM MINNEAPOLIS, 5., 1997, Minneapolis. Proceedings... St. Joseph: ASAE, 1997. p. 563-567. 
LANA, R. P. CAMARDELLI, M. M.; RODRIGUES, M. T.; EIFERT, E. C.; OLIVEIRA, M. V. M.; SATRADIOTTI JUNIOR, D.; OLIVEIRA, J. S. Óleo de soja e própolis na alimentação de cabras leiteiras: consumo de matéria seca e de nutrientes e parâmentos de fermentação ruminal. Revista Brasileira de Zootecnia, Viçosa, v. 36, n. 1, p. 191-197, 2007.

MARQUES, J. A. O stress e a nutrição de bovinos. Maringá: Imprensa Universitária, 2000. 42 p.

MARTIN, P.; BATENSON, P. Measuring behavior an introdoctury guide. Cambridge: Cambridge University Press, 1986. 177 p.

MERTENS, D. R. Regulation of forage intake. In: FAHAY JUNIOR, G. C.; COLLINS, M.; MERTENS, D. R.; MOSER, L. E. (Ed.). Forage quality evaluation and utilization. Madison: American Society of Agronomy, Crop Science of America, Soil Science of America, 1994. p. 233-264.

MOTT, G. O.; LUCAS, H. L. The design, conduct and interpretation of grazing trials on cultivated and improved pastures. In: INTERNACIONAL GRASSLAND CONGRESS, 1952, Pensylvania. Proceedings... Pensylvania: State College Press, 1952. p. 1380-1385.

O'REAGAIN, P. J.; MENTIS, M. T. The effect of plant structure on the acceptability of different grass species to cattle. Journal of Grassland Society of Souther Africa, Joanesburgo, v. 6, n. 3, p. 163-170, 1989.

OLIVEIRA, J. S.; QUEIROZ, A. C.; LANA, R. P.; MANTOVANI, H. C.; GENEROSO, R. A. R. Efeito da monensina e da própolis sobre a atividade de fermentação de aminoácidos in vitro pelos microrganismos ruminais. Revista Brasileira de Zootecnia, Viçosa, v. 35, n. 1, p. 275-281, 2006.

ORR, R. J. S.; RUTTER, S. M.; PENNING, P. D. Matching grass supply to grazing patterns for dairy cows. Grass and Forage Science, London, v. 56, n. 35, p. 352361, 2001.

OTERO, W. G. Avaliação da diversidade microbiana e degradabilidade in situ em animais tratados com preparado de anticorpos policlonais contra bactérias produtoras de lactato e bactérias proteolíticas. 2008. Dissertação (Mestrado em Produção e Nutrição Animal) - Universidade do Estado de São Paulo, Pirassununga.

PEREIRA, A. S.; SEIXAS, F. R. M. S.; AQUINO NETO, F. R. Própolis: 100 anos de pesquisa e suas perspectivas futuras. Química Nova, São Paulo, v. 25, n. 2, p. 321-326, 2002 .
PHILLIPS, C. J.; RIND, M. I. The effects of social dominance on the production and behavior of grazing dairy cows offered forage supplements. Journal of Dairy Science, Champaign, v. 85, n. 1, p. 51-59, 2001.

POLI, C. H. E. C.; MONTEIRO, A. L. G.; BARROS, C. $\mathrm{S}$. Produção de ovinos de corte em quatro sistemas de produção. Revista Brasileira de Zootecnia, Viçosa, v. 37 , n. 4, p. 666-673, 2008.

PRACHE, S. Intake rate, intake per bite and time per bite of lactating ewes on vegetative and reproductive swards. Applied Animal Behavior Science, Dijon, v. 52, n. 5, p. 53-64, 1997.

PRADO, O. P. P. Produto à base de própolis na nutrição de ruminantes (LLOS). 2005. Dissertação (Mestrado em Zootecnia) - Universidade Estadual de Maringá, Maringá.

PRADO, O. P. P.; ZEOULA, M. L.; MOURA, L. P. P.; FRANCO, S. L.; PAIVA, S. B.; ARCURI, P. B. Isolation and expeditious morphological, biochemical and kinetic characterization of própolis-tolerant ruminal bacteria. Revista Brasileira de Zootecnia, Viçosa, v. 39, n. 9, p. 2048-2054, 2010.

RIBEIRO JÚNIOR, J. I.; MELO, A. L. P. Guia prático para utilização do sistema de análise estatística e genética. Viçosa, MG: Universidade Federal de Viçosa, 2008. 288 p.

SALLA, L. E.; MORENO, C. B.; FERREIRA, E. X.; FISCHER, V.; STUMPF, W.; SILVA, M. A. Avaliação do comportamento ingestivo de vacas jersey em lactação: aspectos metodológicos. In: REUNIÃO ANUAL DA SBZ, 1999, Porto Alegre. Anais... Porto Alegre: SBZ, 1999. $68 \mathrm{p}$.

SARMENTO, D. O. L. Comportamento ingestivo de bovinos em pastos de capim Marandu submetido a regime de lotação contínua. 2003. Dissertação (Mestrado em Zootecnia) - Universidade de São Paulo, Escola Superior de Agricultura Luiz de Queiroz, Piracicaba.

SILVA, D. J.; QUEIROZ, A. C. Análises de alimentos. 3. ed. Viçosa, UFV: Imprensa Universitária, 2002. 235 p.

SILVA, R. G. da. Introdução à bioclimatologia animal. São Paulo: Nobel, 2000. 87 p.

SOUZA, M. S. Comportamento ingestivo de bovinos em sistema de pastejo rotacionado submetidos a diferentes estratégias de suplementação. 2007. Tese (Doutorado em Zootecnia) - Universidade Estadual Paulista, Jaboticabal.

SWENSON, M. J. Dukes - fisiologia dos animais domésticos. Rio de Janeiro: Ed. Guanabara Koogan S. A., 1988.799 p. 
VAN SOEST, P. J. Nutritional ecology of the ruminant. 2. ed. London: Constock Publishing Associates. 1994. 476 p.

WALDO, D. R. Effect of forage quality on intake and forage - concentrate. Journal of Dairy Science, Champaign, v. 69, n. 4, p. 617-631, 1986.

WELCH, J. G.; HOOPER, A. P. Ingestion de alimentos y agua. In: CHURCH, D. C. El rumiante: fisiologia digestiva y nutrición. Zaragoza: Acribia, 1982. p. 117126.
WILM, H. G.; COSTELlO, O. F.; KLIMPPLE, G. E. Estimating forage yield by the double sampling method. Journal of American Society of Agronomy, Madison, v. 36, n. 1, p. 194-203, 1944.

ZANINE, A. M.; SANTOS, E. M.; PARENTE, H. N.; FERREIRA, D. J.; CECON, P. R. Comportamento ingestivo de bezerros em partes de Brachiaria brizantha e Brachiaria decumbens. Ciencia Rural, Santa Maria, v. 36, n. 5, p. 1540-1545, 2006. 
